\section{Inoculation with Ericoid Mycorrhizal Fungi Alters Fertilizer Use of Highbush Blueberry Cultivars}

\author{
Carolyn F. Scagel ${ }^{1}$ \\ U.S. Department of Agriculture, Agricultural Research Service, Horticultural \\ Crops Research Unit, 3420 NW Orchard Avenue, Corvallis, OR, 97330
}

\section{Additional index words. Vaccinium corymbosum}

\begin{abstract}
Seven highbush blueberry cultivars were inoculated with one of three different isolates of ericoid mycorrhizal fungi (EMF) and grown in pots for 2 years with either inorganic or organic fertilizer. Root colonization of noninoculated plants was low $(<15 \%)$ regardless of fertilizer source. Root colonization on inoculated plants was $15-30 \%$. Colonization was typically higher when plants were grown with organic fertilizer. Inoculation generally increased plant growth but decreased root:shoot biomass ratios regardless of the type of fertilizer used. Inoculation also increased nutrient uptake and/or nutrient use efficiency in several cultivars, particularly when plants were fertilizer with organic fertilizer. Without inoculum, however, some cultivars fertilized with organic fertilizer had less growth and lower concentrations of $\mathrm{N}, \mathrm{K}, \mathrm{S}$, and $\mathrm{Cu}$ than those fertilized with inorganic fertilizer. Cultivars that were genetically close in ancestry showed a high degree of variability in response to mycorrhizal fungi, while responses to fertilizer type were similar in closely related cultivars. Results suggest that nutrient availability may influence colonization and growth responses to EMF; however aspects of fungus-host specificity and inoculum availability also play a role in EMF colonization of roots in container production.
\end{abstract}

Ericoid mycorrhizal fungi (EMF) form symbiotic associations with roots of blueberry plants as well as other ericaceous plants and can increase their uptake of soil nutrients (Read, 1996). The association is common in both wild and cultivated blueberry plants and can occur during nursery production (Scagel et al., 2005a). In nurseries, however, colonization by EMF is often sporadic and can be quite low depending on cultivar and the method of plant production (Scagel et al., 2005a, 2005b). Low levels of colonization may be a result of nursery cultural conditions, low availability of EMF propagules, and aspects of plant-fungus compatibility. Inoculation has been shown to increase growth of tissue-cultured highbush blueberries in northeastern U.S. (Yang et al., 2002).

The nursery industry is searching for methods to decrease the content of nutrients in effluent from production areas, reduce fertilizer consumption and costs, and maintain a level of available nutrients that does not limit productivity. The ability of EMF to enhance uptake of soluble inorganic $\mathrm{N}$ and $\mathrm{P}$ and utilize organic or insoluble $\mathrm{N}$ and $\mathrm{P}$ compounds in the soil is ecologically important in the nutrition

Received for publication 14 Sept. 2004. Accepted for publication 7 Oct. 2004. The author gratefully acknowledges the technical assistance of Kathleen Eggemeyer, Jesse Mitchell, Lisa Tribbett, Benjamin Jackson, Summer Hendricks, and Jennifer Dutton. We also thank R. Paul Schreiner and David Bryla for their constructive comments on an earlier version of this manuscript and Fall Creek Farm and Nursery Inc., Lowell, Ore., for the donation of plant material. Mention of a trademark, proprietary product, or vendor does not constitute a guarantee or warranty of the product by the U.S. Dept. of Agriculture and does not imply its approval to the exclusion of other products or vendors that also my be suitable.

${ }^{1}$ E-mail scagelc@onid.orst.edu. of ericaceous plants in the wild (Michelsen et al., 1996; Read, 1996). Under horticultural conditions for blueberry where nutrient availability is manipulated by the grower the role of this symbiotic relationship has not been well defined. Inoculation with EMF may not only improve productivity and quality of nursery plants it also may reduce the amount of fertilizer used during nursery production.

In this study, we investigated the potential role EMF play in container-grown blueberry production. Specifically, we determined whether growth and nutrition of highbush blueberry is influenced by inoculation with various EMF isolates, and whether the response to EMF is altered by the type of fertilizer used.

\section{Materials and Methods}

Inoculum production. Three isolates of EMF, Oidiodendron griseum Robak (ATCC 60377, isolated from Vaccinium corymbosum 'Blueray'), Pezizella ericae Pearson et Read (ATCC 32985, isolated from ericaceous roots), and Hymenoscyphus ericae (Read) Korf \& Kernan(UAMH 5828, isolated from Vaccinium angustifolium L.) were used as inoculum. Each isolate was grown in sterile liquid culture of modified Melins-Norkrans agar medium (Molina and Palmer, 1982), harvested by filtration (on the day of inoculation), fragmented with a blender, and suspended in $1 \mathrm{~L}$ sterile water. Inoculum concentrations were determined by aseptically transferring $0.25 \mathrm{~mL}$ of hyphal suspension of each isolate onto agar media (4 replicate plates per isolate) and incubating for $7 \mathrm{~d}$ at $20^{\circ} \mathrm{C}$ before counting the number of colony forming fragments. The average concentration of each isolate in the inoculum was $21.2,6.9$, and $15.1 \mathrm{cfu} / \mathrm{mL}$ for $O$. griseum, $P$. ericae, and $H$. ericae, respectively.
Experimental treatments. In March 2001, rooted tissue culture plantlets (about 6 weeks old) of seven highbush blueberry (Vaccinium corymbosum L.) cultivars ('Bluecrop', 'Blueray', 'Darrow', 'Earliblue', 'Georgia Gem', 'Patriot', and 'Spartan') were obtained from a commercial nursery. Plantlets had been grown in 80-mL-cell flats in a proprietary peat-based growing medium that had been steam pasteurized before sticking unrooted cuttings. Plants were transplanted into 1-L pots filled with a 4:1 mix of composted douglas-fir bark (Whitney Farms, Independence, Ore.) and sphagnum peat (Sunshine Grower Grade White, SunGrow, Hubbard, Ore.). Half of the ports were amended with $5.5 \mathrm{~g} \cdot \mathrm{L}^{-1}$ of inorganic slow-release fertilizer (Osmocote Plus 15-9-12, Scotts Company, Marysville, Ohio; $7 \% \mathrm{NH}_{4}-\mathrm{N}, 8 \% \mathrm{NO}_{3}-\mathrm{N}, \mathrm{P}$ as $\mathrm{P}_{2} \mathrm{O}_{5}$ and $\mathrm{K}$ as $\mathrm{K}_{2} \mathrm{O}$ ) and the other half was amended with $9.1 \mathrm{~g} \cdot \mathrm{L}^{-1}$ of organic fertilizer (BioGro 9-3-5, Warrenton, Ore.; $0.2 \mathrm{NH}_{4}-\mathrm{N}$, $6.5 \%$ water insoluble $\mathrm{N}, 2.3 \%$ water soluble $\mathrm{N}, \mathrm{P}$ as $\mathrm{P}_{2} \mathrm{O}_{5}$, and $\mathrm{K}$ as $\mathrm{K}_{2} \mathrm{O}$ ). Both fertilizers were directly mixed into the potting media. The organic fertilizer provided the same amount of total $\mathrm{N}$ to each pot as inorganic fertilizer, but $45 \%$ less $\mathrm{P}$ and $31 \%$ less $\mathrm{K}$. Pots were then drenched with $50 \mathrm{~mL}$ of inoculum solution from one of the three EMF isolates or $50 \mathrm{~mL}$ of distilled water (noninoculated controls). Overall, there were 10 plants per cultivar for each inoculum and fertilizer treatment for a total of 560 plants.

Plant culture. Plants were maintained in a glasshouse (16h supplemental light and average day/night temperatures of $21 / 16^{\circ} \mathrm{C}$ ) for 4 weeks after transplanting. Plants were then transferred to an outdoor growing area in Corvallis, OR (445' $\left.287^{\prime \prime} \mathrm{N}, 123^{\circ} 29^{\prime} 739^{\prime \prime} \mathrm{W}\right)$ until they were moved to a plastic-covered, open-ended hoophouse in December 2001 for winter frost protection. In March 2002, plants were removed from the hoophouse, transplanted to 4-L pots filled with the douglas-fir bark:sphagnum peat mix, and again placed in the outdoor growing area. The mix was top-dressed with the same type and rate of fertilizer described above; equal amounts of fertilizer were mixed into the top 5 $\mathrm{cm}$ of medium in each pot. Plants were watered as needed throughout the study. During each growing season, leachate was collected from the pots every 2 weeks and measured for $\mathrm{pH}$.

Measurements. In September 2001 and 2002, five plants from each treatment were harvested. Shoots were washed, separated into stem and leaf components, dried at $60^{\circ} \mathrm{C}$ for at least $48 \mathrm{~h}$, and weighed. A 5-g (fresh wt.) subsample of roots was washed from the pots, cleared and stained following procedures outlined in Scagel et al. (2005a), and stored in lactoglycerin solution for later determination of EMF colonization. The remaining roots in the pots were washed, dried, and weighed. EMF colonization was determined as the percentage of fresh root segments containing internal mycorrhizal structures quantified using a grid-line intersect technique (Newman, 1985) modified to determine percentage of cells infected (Giovannetti and Mosse 1980). Dried leaf, stem, and root samples were analyzed for $\mathrm{N}$ and $\mathrm{S}$ by automated combustion and for $\mathrm{P}$, $\mathrm{K}, \mathrm{Ca}, \mathrm{Mg}, \mathrm{Fe}, \mathrm{Mn}, \mathrm{Cu}, \mathrm{B}$, and $\mathrm{Zn}$ by dry ash 
oxidation and ICP-AES. Total content of different nutrients in plants was calculated from the sum of the total nutrients in each tissue type (e.g., leaves, stems, roots) based on weight and nutrient concentration of each tissue. Average concentration of different nutrients per plant was calculated by dividing the total content of each nutrient by total plant biomass.

Statistical analyses. Treatments were arranged in a completely randomized design with five replicates per treatment at each harvest. Plant dry weights and root colonization were analyzed using multifactor analysis of variance (ANOVA). When ANOVA indicated no significant interactions $(P>0.05)$ between harvest date and other main effects for colonization and biomass data, data from both years were combined for analyses. To determine the influence of inoculation with EMF on root colonization of different cultivars, contrasts were used to group cultivars based on differences between noninoculated plants and plants inoculated with the different EMF isolates. To assess whether highbush blueberry root colonization responses to EMF inoculation are altered by fertilizer type, contrasts were used to compare noninoculated plants grown with different fertilizer types to plants inoculated with the different EMF isolates. To determine the influence of inoculation with EMF on biomass of different cultivars, contrasts were used to compare noninoculated plants to plants inoculated with EMF (all isolates combined). Root colonization and nutritional data were square-root transformed and prior to analysis to correct for unequal variance and achieve best model fit. Back-transformed least squares means of actual data are reported in tables and figures. Where appropriate, Bonferroni test was used to separate treatment means $(P<0.05)$. Nutrient concentration and content data were analyzed using Kruskal-Wallis ANOVA. Nutrient results are presented only for selected nutrients representing specific responses to treatments. Combined growth, nutrient concentration, and nutrient content differences between treatments were used to categorize nutritional responses to treatments within each cultivar, by comparing differences between treatments to noninoculated plants grown with inorganic fertilizer. Categories derived from these data included: $\mathrm{D}=$ nutrient limited, decreases in concentration and content (Kruskal-Wallis ANOVA, $P<0.05$ ) limiting biomass (Bonferroni's test, $P<0.05$ ). $\mathrm{S}=$ nutrient sufficient, changes in concentration do not influence growth. $\mathrm{E}=$ efficiency of nutrient use increase, increases in biomass with significant decreases in concentration and content. $\mathrm{L}=$ luxury consumption or storage of nutrient, increases in concentration and content do not influence growth. $\mathrm{U}=$ availability or uptake of nutrient enhanced, increases in concentration and content proportionately related to increases in growth. All analyses were performed using the Statistica statistical package (Statsoft, Inc., Tulsa, Okla.).

\section{Results}

Root colonization. Colonization of roots by EMF generally increased between the first and second growing season, however differences due to cultivar, fertilizer, and inoculation treatments were similar between growing seasons (data not shown). Noninoculated plants of all cultivars showed low levels $(<15 \%)$ of colonization by EMF (Fig. 1A). Plants of 'Bluecrop', and 'Georgia Gem' had the highest levels of root colonization when inoculated with the O. griseum isolate, while plants of 'Spartan' had highest levels of root colonization when inoculated with the P. ericae isolate (Fig. 1A). Although the intensity of root colonization by EMF of the different cultivars varied with isolate of EMF used for inoculation, $>95 \%$ of the variation in root colonization attributed to EMF inoculation treatments by ANOVA was due to root colonization differences between noninoculated and inoculated plants and $<5 \%$ of the variation was due to colonization differences between EMF isolates. Plants grown with organic fertilizer generally had higher levels of colonization regardless of cultivar (nonsignificant cultivar $\times$ fertilizer interaction). Fertilizer type had no effect on colonization of noninoculated plants or plants inoculated with H. ericae while plants inoculated with the other isolates had higher colonization when grown with organic fertilizers than with inorganic fertilizers (Fig. 1B).

Growth in response to fertilizer type. Differences in morphology and biomass associated with fertilizer type during the first growing season were similar but of lower magnitude than differences detected during the second growing season (data not shown). Leaf, stem, and root biomass was influenced in different ways by fertilizer type depending on cultivar (Fig. 2A). Plants of 'Bluecrop', 'Blueray', 'Darrow', and 'Earliblue' had lower leaf, stem, and root biomass when grown with organic
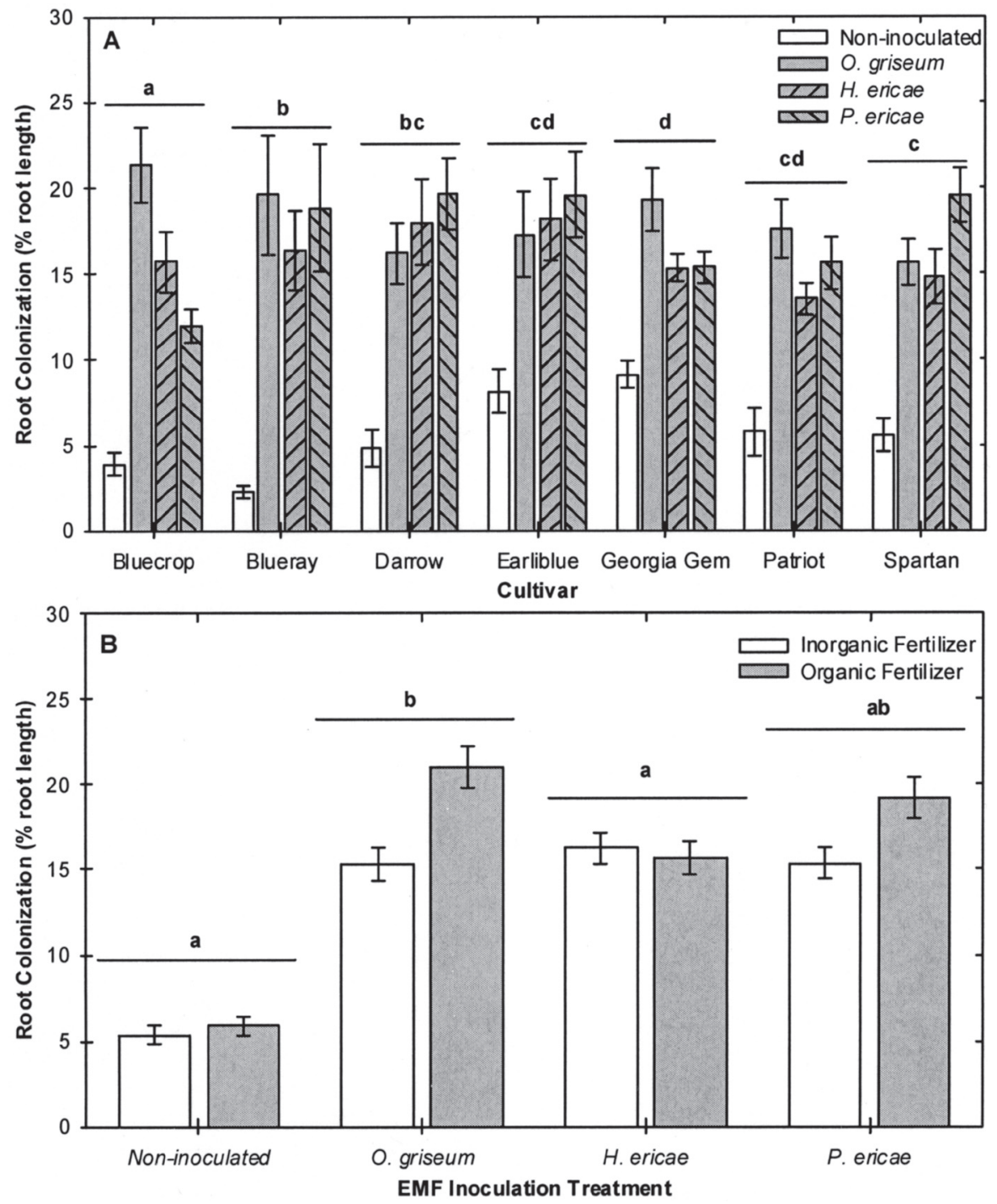

Fig. 1. Influence of (A) inoculation with ericoid mycorrhizal fungi (EMF) on root colonization of container-grown blueberry (Vaccinium corymbosum) cultivars, and (B) influence of EMF-inoculation on root colonization response to fertilizer type. EMF inoculation treatments: noninoculated, Oidiodendron griseum, Hymenoscyphus ericae, Pezizella ericae. Fertilizers types: inorganic, organic. Columns represent means averaged over two growing seasons of (A) 20 (combined over fertilizer treatments) and (B) 70 replications (combined over cultivars). Bars on columns represent least significant differences based on Bonferroni's test $(P<0.05)$. Groups of columns with the same letters above them $(\mathbf{B})$ represent similar responses between EMF inoculation treatments to fertilizer type, based on orthogonal contrasts $(P<0.05)$. 
fertilizer than with inorganic fertilizer. Stem and leaf biomass was lower when plants of 'Patriot'were grown with organic fertilizer than with inorganic fertilizer, but root biomass was greater when plants were grown with organic fertilizer. Plants of 'Georgia Gem' and 'Spartan' had lower leaf biomass and higher root biomass when grown with organic fertilizer than with inorganic fertilizer. Plants grown with organic fertilizers partitioned a higher proportion of total biomass to roots than plants grown with inorganic fertilizer regardless of cultivar (Fig. 2A). For 'Bluecrop', 'Blueray', 'Georgia Gem', 'Patriot', and 'Spartan' this difference in partitioning appeared to be at the expense of leaf biomass, while for 'Darrow' and 'Earliblue' partitioning to both leaves and stems was influenced by fertilizer type.

Growth in response to EMF inoculation.
Differences in morphology and biomass associated with mycorrhizal inoculum during the first growing season were similar but of lower magnitude than differences detected during the second growing season (data not shown). Biomass responses to inoculation did not significantly differ between EMF isolates, however, leaf, stem, and root biomass was influenced in different ways by inoculation depending on cultivar (Fig. 2B). Leaf biomass of 'Bluecrop', 'Earliblue', 'Georgia Gem', and 'Patriot' was increased by EMF inoculation, stem biomass of all cultivars but 'Spartan' was increased by EMF inoculation, and root biomass of all cultivars except 'Patriot' and 'Spartan' was increased by EMF inoculation. EMF-inoculated plants generally partitioned less biomass to roots and more to stems than noninoculated plants (Fig. 2B). EMF-inocula-
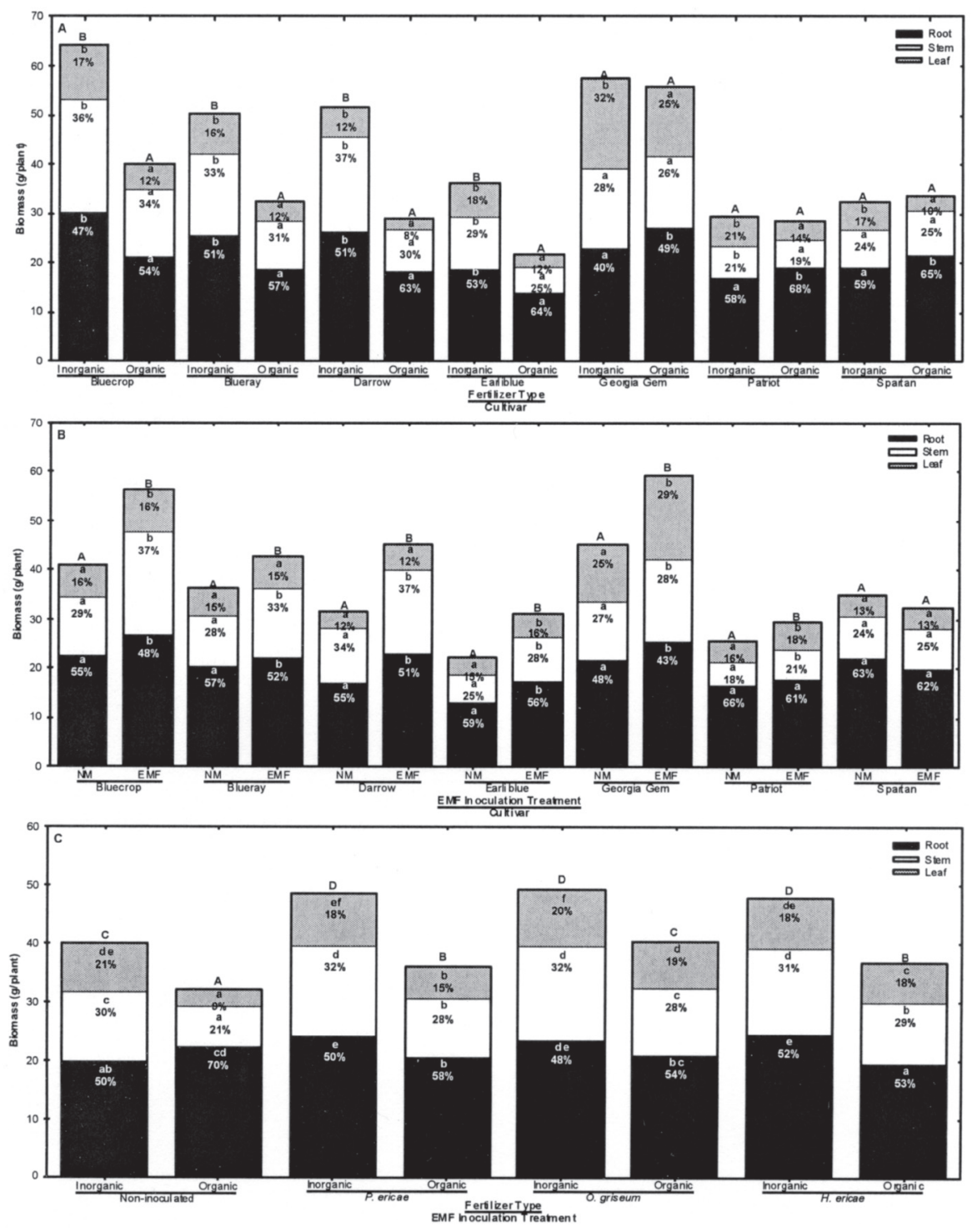

Fig. 2. Influence of fertilizer type and inoculation with ericoid mycorrhizal fungi (EMF) on root, stem, and leafbiomass of container-grown blueberry (Vaccinium corymbosum) cultivars. Fertilizers types: inorganic, organic. EMF inoculation treatments: noninoculated (NM), Oidiodendron griseum, Hymenoscyphus ericae, Pezizella ericae. Columns represent means averaged over two growing seasons of (A) 40, (B) 20 (NM) or 60 (EMF), (C) 70 replications. Columns with the same upper case letters above them within a cultivar (A and $\mathbf{B})$ or across treatments $(\mathbf{C})$ are not significantly different from each other (Bonferroni's test, $P<0.05)$. Means for roots, stems, and leaves within a cultivar (A and $\mathbf{B})$ or across treatments $(\mathbf{C})$ designated with the same lower case letter are not significantly different from each. Numbers within columns are percentage of total plant biomass partitioned to different plant tissues. tion increased biomass partitioning to leaves in only two cultivars, 'Georgia Gem' and 'Patriot'.

Fertilizer influence on growth in response to EMF inoculation. Leaf and stem biomass responses to fertilizer type were similar regardless of EMF-inoculation treatment, however, root biomass response to fertilizer varied with EMF inoculation treatment (Fig. 2C). Although leaf and stem biomass of plants grown with organic fertilizer was lower than plants grown with inorganic fertilizer, leaf and stem biomass of noninoculated plants was lower than EMF-inoculated plants when plants were grown with organic fertilizer. Root biomass of noninoculated plants was higher when plants were grown with organic fertilizer than with inorganic fertilizer, while inoculated plants had lower root biomass when grown with organic fertilizer than with inorganic fertilizer. Noninoculated plants partitioned less biomass to leaves and stems and more biomass to roots when grown with organic fertilizer than with inorganic fertilizer while partitioning of biomass to leaves of EMF-inoculated plants was not influenced by fertilizer type (Fig. 2C).

Cultivar and tissue variation in nutrient concentrations. The $\mathrm{pH}$ of leachates collected from pots in both growing seasons was highly variable and ranged between 5.1 to 5.8 and was not significantly different between cultivars, fertilizer type or inoculation treatments. There was a large range of macronutrient $(\mathrm{N}, \mathrm{P}, \mathrm{K}$, $\mathrm{S}, \mathrm{Ca}, \mathrm{Mg}$ ) and micronutrient $(\mathrm{Mn}, \mathrm{Fe}, \mathrm{Cu}, \mathrm{B}$, $\mathrm{Zn})$ concentrations in stems, leaves and roots and concentrations varied with cultivar (Table 1), fertilizer type and inoculation with EMF. In general, leaves had higher concentrations of $\mathrm{N}, \mathrm{P}, \mathrm{K}, \mathrm{S}$, and B than roots or stems, while roots had higher concentrations of $\mathrm{Fe}, \mathrm{Cu}$, and $\mathrm{Zn}$. Concentrations of all nutrients in leaves except for $\mathrm{Ca}, \mathrm{Fe}, \mathrm{Cu}$ and $\mathrm{B}$ fell within the 'normal' ranges reported by others (Table 1). Lower than 'normal' leaf Ca was measured in all cultivars except 'Georgia Gem', low Fe and $\mathrm{Cu}$ was measured in leaves of all cultivars, and low leaf B was measured in all cultivars except 'Earliblue' and 'Darrow'. Leaf nutrients occurring at concentrations higher than the 'normal' ranges included $\mathrm{N}, \mathrm{K}$ and $\mathrm{Mg}$ and were found in all cultivars. Regardless of tissue type, concentrations of N, K, S, and $\mathrm{Cu}$ were positively correlated with each other and negatively correlated with concentrations of $\mathrm{Ca}$ and $\mathrm{Mg}$ (data not shown). Correlations between nutrients sometimes varied with tissue type. For example, $\mathrm{P}$ concentrations in stems and leaves were positively correlated with $\mathrm{N}, \mathrm{K}$, and $\mathrm{S}$ concentrations while in roots $\mathrm{P}$ concentrations were negatively correlated with $\mathrm{N}, \mathrm{K}$, and $\mathrm{S}$ concentrations. A similar change in relationship was also seen between $\mathrm{P}$ and $\mathrm{Zn}$ concentrations in leaves and roots. Also, $\mathrm{N}$ and Fe concentrations in leaves were positively correlated while in roots and stems $\mathrm{Fe}$ and $\mathrm{N}$ were negatively correlated.

Fertilizer effects on total nutrient uptake. Fertilizer type significantly influenced average content of most nutrients and the magnitude of response to the different fertilizers varied between cultivars. For all cultivars, plants took 


\begin{tabular}{|c|c|c|c|c|c|c|c|c|c|c|c|}
\hline \multirow[b]{2}{*}{ Cultivar $^{2}$} & \multicolumn{11}{|c|}{${\text { Nutrient } \text { range }^{z}\left(\mathrm{mg} \cdot \mathrm{g}^{-1}\right)}$} \\
\hline & $\mathrm{N}$ & $\mathrm{P}$ & $\mathrm{K}$ & $\mathrm{S}$ & $\mathrm{Ca}$ & $\mathrm{Mg}$ & $\mathrm{Mn}$ & $\mathrm{Fe}$ & $\mathrm{Cu}$ & B & $\mathrm{Zn}$ \\
\hline \multicolumn{12}{|l|}{ Leaf } \\
\hline Bluecrop & $17-29$ & $2.3-3.3$ & $6.2-9.2$ & $1.17-1.67$ & $2.4-4.8$ & $1.8-3.0$ & $75-116$ & $41-59$ & $2.2-3.9$ & $18-28$ & $23-33$ \\
\hline Blueray & $17-33$ & $2.1-3.9$ & $6.6-10.5$ & $1.39-2.16$ & $3.4-4.6$ & $2.4-2.9$ & $64-127$ & $35-50$ & $3.2-4.8$ & $22-27$ & $26-38$ \\
\hline Darrow & $22-39$ & $3.9-5.2$ & $9.4-15.5$ & $1.69-2.40$ & $3.3-5.9$ & $2.5-3.6$ & $75-139$ & $48-79$ & $3.7-5.7$ & $33-40$ & $30-52$ \\
\hline Earliblue & $17-33$ & $2.2-3.9$ & $6.7-10.8$ & $1.32-2.15$ & $3.9-5.8$ & $2.2-3.1$ & $77-184$ & $32-68$ & $2.4-4.5$ & $55-32$ & $24-37$ \\
\hline Spartan & $17-32$ & $2.1-3.1$ & $7.2-11.3$ & $1.29-2.28$ & $3.2-5.6$ & $1.9-3.2$ & $79-150$ & $41-72$ & $2.1-3.7$ & $20-31$ & $22-30$ \\
\hline Patriot & $16-30$ & $2.0-3.0$ & $6.2-11.6$ & $1.28-2.35$ & $3.3-5.9$ & $2.4-3.0$ & $89-168$ & $40-74$ & $2.2-3.6$ & $22-30$ & $19-28$ \\
\hline Georgia Gem & $19-25$ & $1.4-2.4$ & $8.2-9.2$ & $1.21-1.78$ & $4.9-5.9$ & $2.2-3.5$ & $118-159$ & $51-77$ & $1.3-4.3$ & $28-39$ & $18-32$ \\
\hline Leaf normaly & $15-25$ & $1.0-4.0$ & $3.5-7.0$ & $1.0-2.4$ & $4.0-8.0$ & $1.2-2.5$ & $50-350$ & $60-200$ & $5-20$ & $30-70$ & $8-30$ \\
\hline \multicolumn{12}{|l|}{ Stem } \\
\hline Bluecrop & $3-9$ & $0.9-1.4$ & $2.6-3.6$ & $0.35-0.68$ & $1.6-6.3$ & $0.8-1.4$ & $122-170$ & $18-65$ & $1.4-1.9$ & $6-13$ & $12-23$ \\
\hline Blueray & $4-10$ & $1.0-1.4$ & $2.4-3.8$ & $0.42-0.64$ & $4.7-8.8$ & $0.8-1.6$ & $120-177$ & $17-70$ & $1.8-2.5$ & $11-15$ & $9-29$ \\
\hline Darrow & $3-9$ & $0.6-1.2$ & $2.2-2.8$ & $0.30-0.69$ & $2.1-4.9$ & $0.5-1.1$ & $67-104$ & $14-38$ & $1.2-1.8$ & $6-12$ & $12-20$ \\
\hline Earliblue & $3-10$ & $0.7-1.2$ & $2.8-3.5$ & $0.39-0.73$ & $4.1-10.3$ & $0.4-1.1$ & $91-152$ & $20-79$ & $1.1-2.0$ & $6-10$ & $16-29$ \\
\hline Spartan & $4-10$ & $0.6-1.0$ & $2.4-3.5$ & $0.38-0.80$ & $3.8-7.8$ & $0.8-1.4$ & $88-146$ & $18-73$ & $1.3-2.2$ & $9-13$ & $13-26$ \\
\hline Patriot & $4-11$ & $0.7-1.0$ & $2.5-3.5$ & $0.52-0.92$ & $4.2-7.6$ & $0.6-0.8$ & $84-179$ & $16-64$ & $1.0-1.8$ & $7-10$ & $17-29$ \\
\hline Georgia Gem & $4-10$ & $0.7-1.2$ & $2.3-3.1$ & $0.36-0.93$ & $4.5-8.1$ & $1.1-1.3$ & $133-183$ & $31-76$ & $1.8-2.8$ & $10-15$ & $25-42$ \\
\hline \multicolumn{12}{|l|}{ Root } \\
\hline Bluecrop & $6-16$ & $0.8-2.6$ & $1.1-2.4$ & $0.61-1.49$ & $4.4-9.5$ & $2.2-2.7$ & $115-176$ & 789-2217 & $4.8-19.5$ & $16-27$ & $91-145$ \\
\hline Blueray & $7-16$ & $0.8-2.2$ & $1.0-1.6$ & $0.91-1.38$ & $4.0-10.4$ & $2.0-3.0$ & $113-159$ & $812-2411$ & $5.1-14.5$ & $15-29$ & $76-152$ \\
\hline Darrow & $5-14$ & $0.8-1.9$ & $1.1-3.0$ & $0.67-1.52$ & $4.0-8.2$ & $1.7-2.2$ & $112-141$ & $1530-2757$ & $3.9-20.1$ & $10-27$ & $72-158$ \\
\hline Earliblue & $6-14$ & $0.8-1.6$ & $1.0-2.1$ & $0.87-1.51$ & $5.0-8.9$ & $1.8-2.6$ & $84-162$ & $1244-2604$ & $4.5-19.6$ & $12-22$ & $82-196$ \\
\hline Spartan & $6-13$ & $0.9-2.3$ & $0.8-1.8$ & $0.71-1.25$ & $4.7-11.9$ & $1.9-2.7$ & $102-155$ & $1620-2341$ & $5.3-8.9$ & $16-22$ & $88-165$ \\
\hline Patriot & $6-12$ & $0.7-2.0$ & $0.7-1.9$ & $0.74-1.32$ & $5.2-10.3$ & $1.9-2.8$ & $83-164$ & $946-1570$ & $4.2-15.9$ & $18-36$ & 79-118 \\
\hline Georgia Gem & $7-17$ & $0.9-1.8$ & $1.0-1.9$ & $0.97-1.47$ & $4.7-7.3$ & $1.8-2.1$ & $95-148$ & 849-1490 & $4.6-14.5$ & $7-9$ & $66-167$ \\
\hline
\end{tabular}

${ }^{\mathrm{z}}$ Minimum and maximum values over two growing seasons all fertilizer types and EMF inoculation treatments.

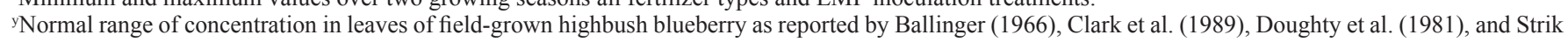
and Hart (1997).
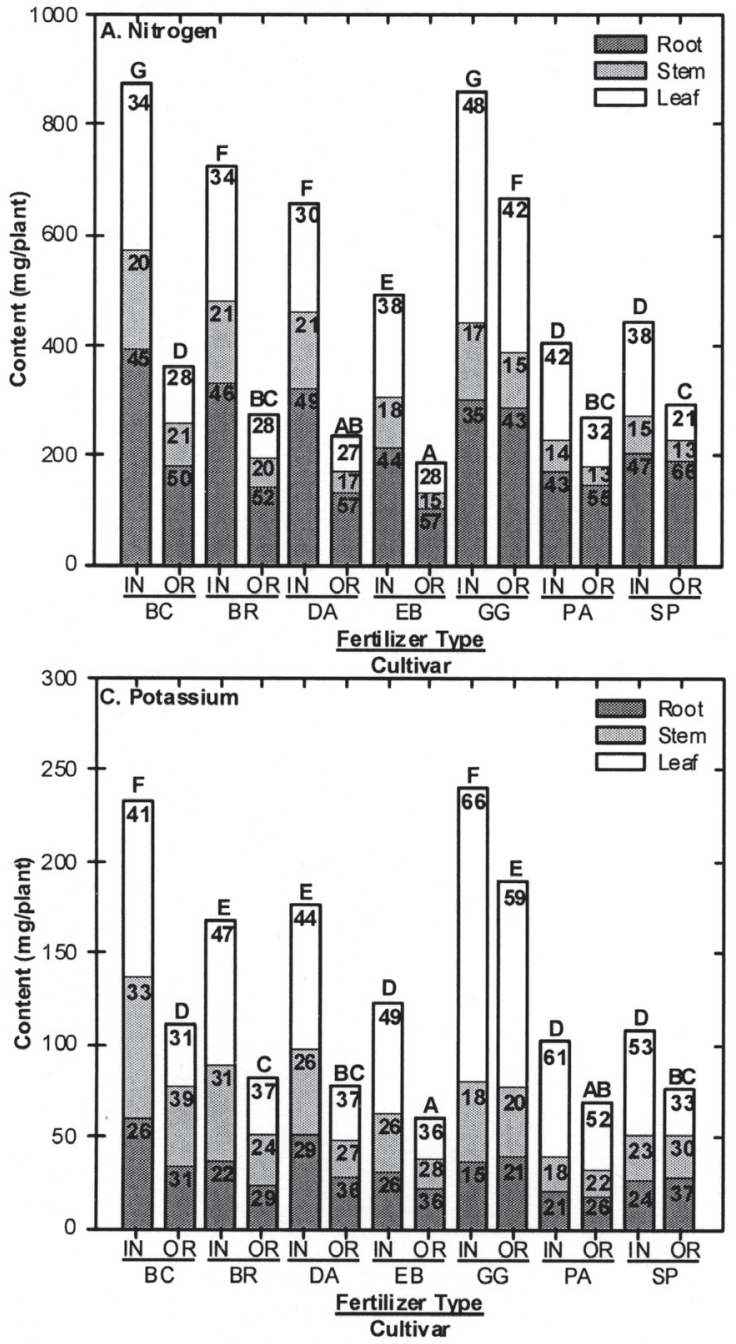
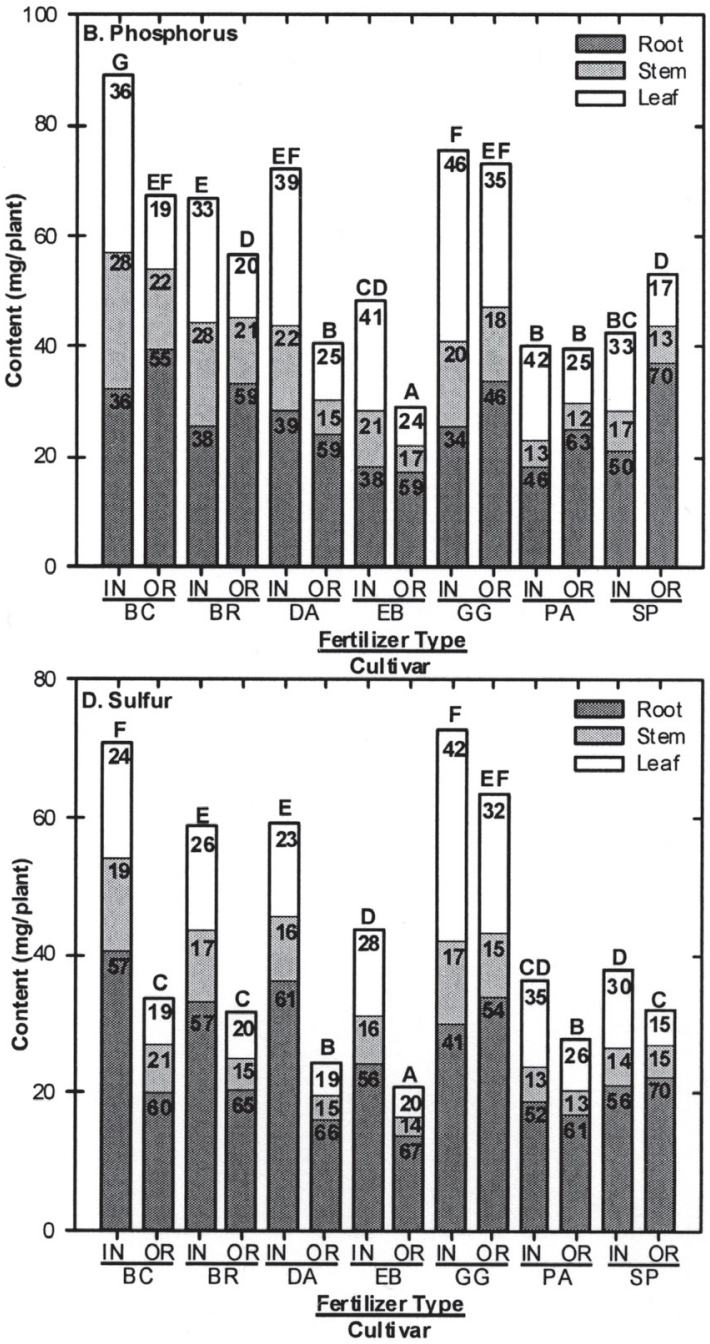

Fig. 3. Influence of fertilizer type on total uptake of nitrogen, phosphorus, potassium, calcium, and magnesium of containergrown blueberry ( $\mathrm{Vac}$ cinium corymbosum) cultivars over 2 years. Cultivars:Bluecrop(BC), Blueray (BR), Darrow (DA), Earliblue (EB), Georgia Gem (GG), Patriot (PA), Spartan (SP). Fertilizers: inorganic (IN), organic (OR). Columns represent means of 20 replications. Columns with the same upper case letters above them within a cultivar are not significantly different from each other (Kruskal-Wallis ANOVA, $P<$ $0.05)$. Numbers within columns are percentage of total nutrient content partitioned to different plant tissues. 
up less N (Fig. 3A), K (Fig. 3C), and S (Fig. $3 \mathrm{D})$ when grown with organic fertilizer than with inorganic fertilizer. 'Bluecrop', 'Blueray', 'Darrow' and 'Earliblue' took up similar or less $\mathrm{P}, \mathrm{Ca}, \mathrm{Mg}, \mathrm{Mn}, \mathrm{Cu}$, and $\mathrm{Zn}$ when grown with organic fertilizer than with inorganic fertilizer while $\mathrm{P}, \mathrm{Ca}, \mathrm{Mg}, \mathrm{Mn}, \mathrm{Cu}$, and $\mathrm{Zn}$ uptake of 'Georgia Gem', 'Patriot' and 'Spartan' was similar or greater when grown with organic fertilizer ( $\mathrm{P}$ shown in Fig. 3B). Across all cultivars and fertilizer types roots contained the highest proportion of total $\mathrm{N}, \mathrm{S}, \mathrm{Ca}, \mathrm{Mg}$, $\mathrm{Fe}, \mathrm{Cu}$, and $\mathrm{Zn}$, and leaves contained the highest proportion of total K. Partitioning of $\mathrm{P}$ to different plant tissues changed with fertilizer type. Plants grown with inorganic fertilizer partitioned similar proportions of total $\mathrm{P}$ to leaves and roots, but when grown with organic fertilizer, roots had the highest proportion of total P. 'Georgia Gem' generally took up more macro and microelements when grown with organic fertilizers than other cultivars.

Effects of EMF-inoculation on total nutrient uptake. Inoculation with EMF significantly influenced average content of all nutrients and the magnitude of response to EMF inoculation varied between cultivars $(\mathrm{N}, \mathrm{P}, \mathrm{K}$, and Zn shown in Fig. 4). Plants inoculated with EMF generally took up more of all nutrients, although nutrient uptake of cultivars 'Patriot' and 'Spartan' was little effected by inocula- tion with EMF. Inoculation with EMF had little influence on partitioning of nutrients to different plant tissues. Across all cultivars and EMF inoculation treatments roots contained the highest proportion of total $\mathrm{P}, \mathrm{S}, \mathrm{Ca}, \mathrm{Mg}$, $\mathrm{Mn}, \mathrm{Fe}, \mathrm{Cu}$, and $\mathrm{Zn}$, and leaves contained the highest proportion of total $\mathrm{K}$.

Fertilizer influence on nutrient uptake response to EMF inoculation. When grown with inorganic fertilizer plants inoculated with the $O$. griseum and $P$. ericae isolates had higher total content of all nutrients than noninoculated plants. Inoculation with $O$. griseum and $P$. ericae isolates when plants were grown with organic fertilizer increased uptake of all nutrients except $\mathrm{Ca}, \mathrm{Fe}$, and $\mathrm{Zn}(\mathrm{N}, \mathrm{P}$, $\mathrm{K}$, and $\mathrm{Ca}$ shown in Fig. 5). Nutrient uptake responses to inoculation with the $H$. ericae isolate varied with nutrient and fertilizer type. For example, plants inoculated with $H$. ericae generally had higher total N, K, Mn, and B content than noninoculated plants when grown with organic fertilizer but inoculation with $H$. ericae had no effect on total uptake of these nutrients when plants were grown with inorganic fertilizer. Conversely, plants inoculated with $H$. ericae generally had higher total $\mathrm{Ca}$ and $\mathrm{Zn}$ when grown with inorganic fertilizer but inoculation with $H$. ericae had no effect on total uptake of these nutrients when plants were grown with organic fertilizer. In general, inoculation with EMF did not alter partitioning of $\mathrm{N}, \mathrm{K}, \mathrm{S}, \mathrm{Mn}, \mathrm{Cu}$, or $\mathrm{Zn}$ when plants were grown with inorganic fertilizer. When plants were grown with organic fertilizer, inoculation with EMF decreased N, K, S, Ca, B, and Mn partitioning to roots and increased partitioning of these nutrients to leaves.

Relationships between nutrition and growth. The influence of EMF inoculation on the relationships between nutrient uptake and growth also varied with cultivar and fertilizer type (Table 2). Growth responses to inoculation with EMF were related to increased nutrient uptake or enhanced availability of different nutrients depending on the cultivar. For example, increased biomass due to inoculation of 'Bluecrop' grown with inorganic fertilizer were related to increased concentrations and content of $\mathrm{Mn}$ and $\mathrm{Cu}$, while increased biomass of 'Darrow' was related to increased concentrations and content of $\mathrm{Ca}, \mathrm{Mg}, \mathrm{Fe}$, and $\mathrm{Cu}$. In general, increased uptake of microelements ( $\mathrm{Fe}, \mathrm{Cu}, \mathrm{B}$, and $\mathrm{Zn}$ ) was most commonly related to growth responses due to inoculation. Inoculation of cultivar 'Georgia Gem' showed the most responsiveness to EMF in terms of increased growth, nutrient concentration, and nutrient content for $\mathrm{N}, \mathrm{S}, \mathrm{Fe}, \mathrm{Cu}$, and $\mathrm{Zn}$ when grown with inorganic fertilizer, and $\mathrm{Mg}, \mathrm{Mn}$, $\mathrm{Fe}, \mathrm{Cu}$, and $\mathrm{Zn}$ when grown with organic fertilizer. When plants were grown with organic
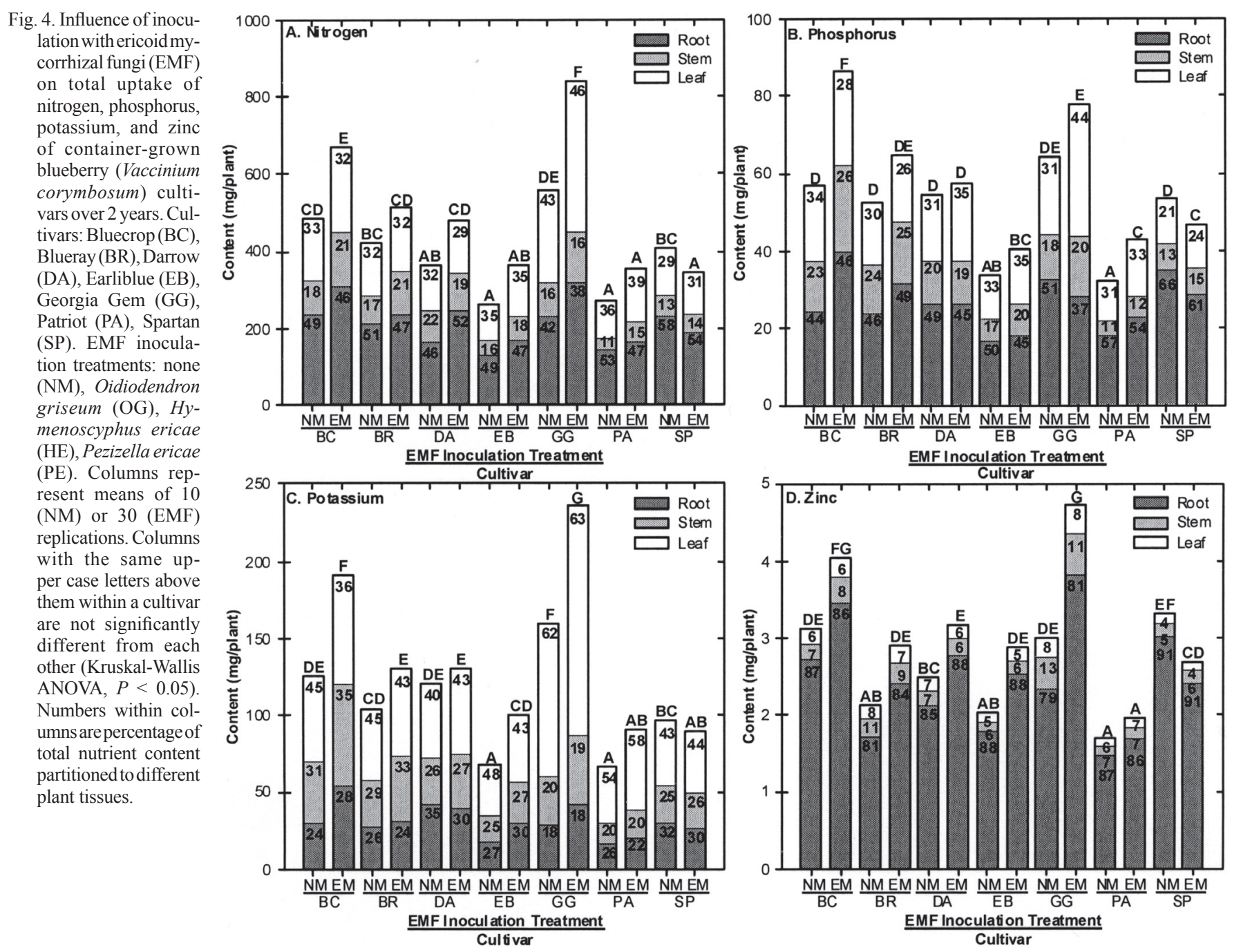

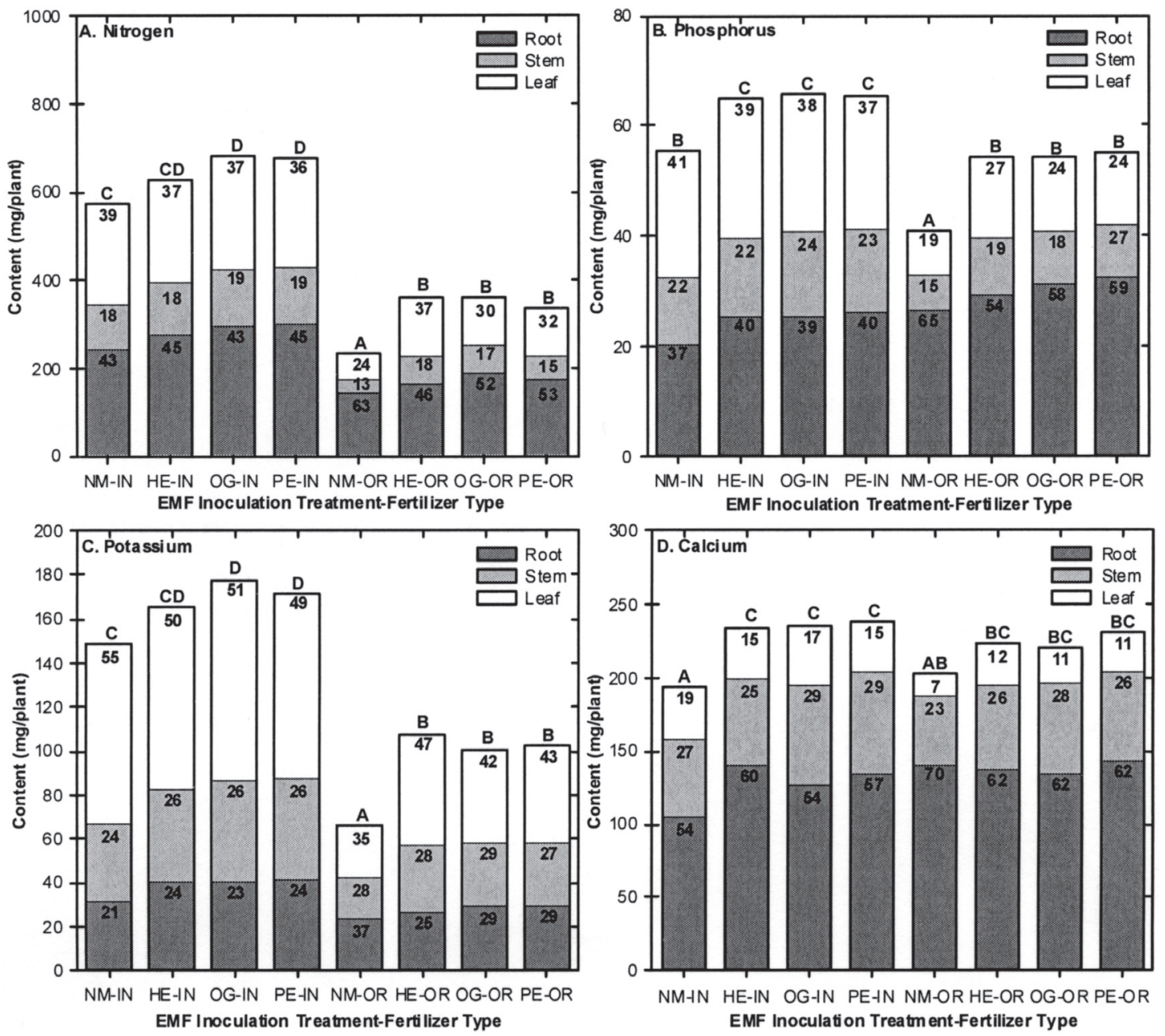

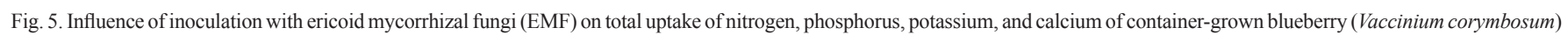
cultivars over 2 years grown with inorganic or organic fertilizers. Fertilizers: inorganic (IN), organic (OR). EMF inoculation: none (NM), Oidiodendron griseum (OG), Hymenoscyphus ericae (HE), Pezizella ericae (PE). Influence of inoculation with ericoid mycorrhizal fungi (EMF) on. EMF inoculation treatments: none (NM), Oidiodendron griseum (OG), Hymenoscyphus ericae (HE), Pezizella ericae (PE). Columns represent means of 35 replicates. Columns with the same upper case letters above them are not significantly different from each other (Kruskal-Wallis ANOVA, $P<0.05$ ). Numbers within columns are percentage of total nutrient content partitioned to different plant tissues.

Table 2. Combined growth and nutritional response of Vaccinium corymbosum to fertilizer type and inoculation with ericoid mycorrhizal fungi (EMF).

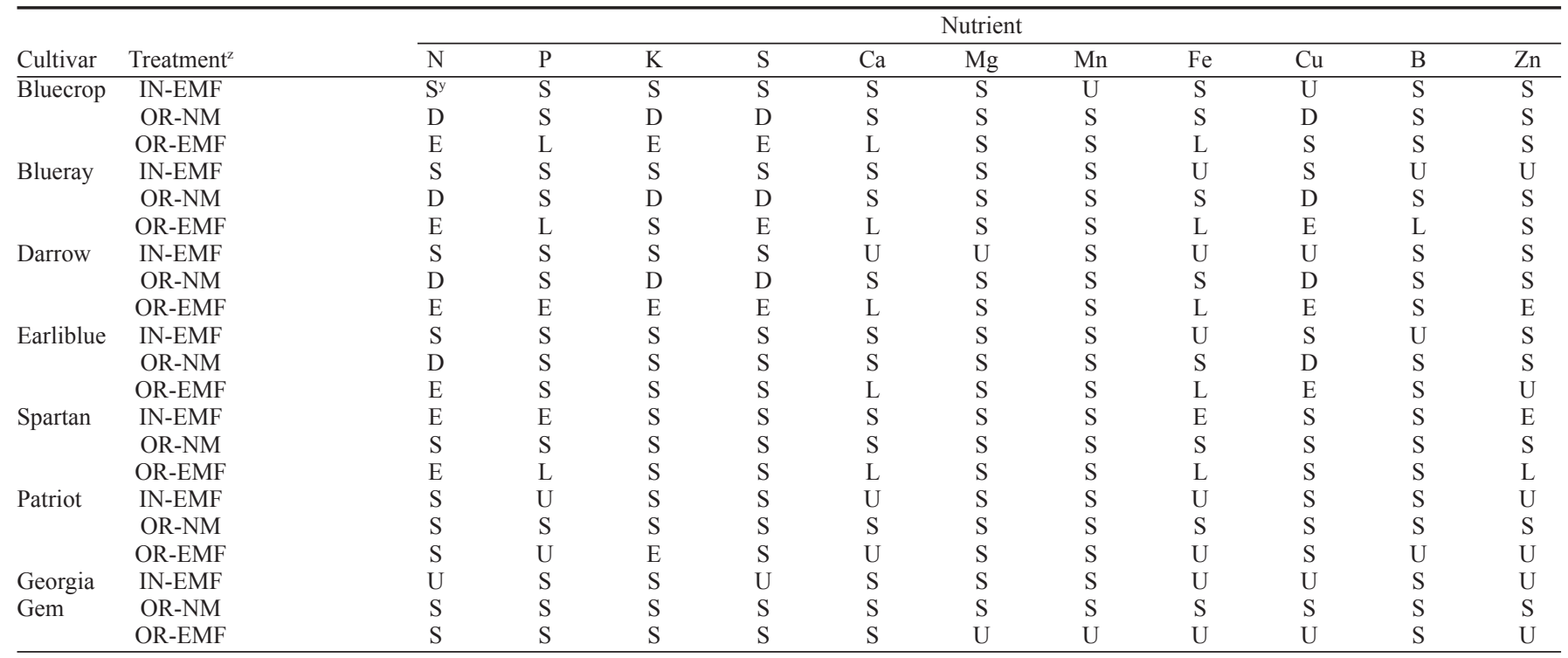

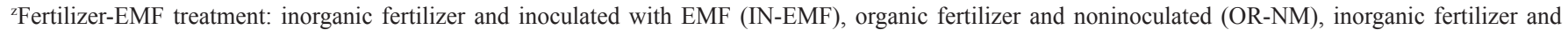
inoculated with EMF (OR-EMF).

${ }^{y}$ Combined nutritional and growth response in comparison to noninoculated plants within the same cultivar grown with inorganic fertilizer. $\mathrm{D}=$ nutrient limited, decreases in concentration and content (Kruskal-Wallis ANOVA, $P<0.05$ ) limiting biomass (Contrast, $P<0.05$ ). $\mathrm{S}=$ nutrient sufficient, changes in concentration do not influence growth. $\mathrm{E}=$ efficiency of nutrient use increase, increases in biomass with significant decreases in concentration and content. $\mathrm{L}=$ luxury consumption or storage of nutrient, increases in concentration and content do not influence growth. $U=$ availability or uptake of nutrient enhanced, increases in concentration and content proportionately related to increases in growth. 
fertilizer, growth of many cultivars may have been limited by lower uptake or availability of $\mathrm{N}, \mathrm{K}, \mathrm{S}$, and $\mathrm{Cu}$ when plants were not inoculated with EMF (Table 2). Inoculation of plants with EMF in all cases alleviated this nutrient limitation and nutrient use was either similar to plants grown with inorganic fertilizer, or plants exhibited a more efficient use of nutrients (e.g., more growth given less nutrients). For some nutrients inoculation with EMF increased concentrations and contents of nutrients without influencing growth.

\section{Discussion}

Without inoculation with EMF, we found that container grown blueberry plants can become naturally colonized with EMF, however root colonization of noninoculated plants was low $(<10 \%)$ regardless of cultivar or fertilizer type (Fig. 1A). This suggests that inoculum potential of the potting mix was low and/or colonization conditions were not conducive to the fungi present. In a commercial blueberry nursery, plants can become naturally colonized by EMF from propagules in the growing media during the first few months of propagation (Scagel et al., 2005b), however the intensity of colonization by EMF indigenous to the potting mix was generally low and that inoculation of unrooted blueberry tissue culture plantlets with EMF increased EMF colonization for some cultivars (Scagel et al., 2005a). In a commercial blueberry nursery, Scagel et al. (2005b) reported that noninoculated plants became mycorrhizal during the first year of production but levels of colonization were generally $<16 \%$. Smagula and Litten (1989) also reported that lowbush bluberry plants from tissue culture could become naturally colonized with EMF during production and Moore-Parkhurst and Englander(1989) reported that Rhododendron spp. can become naturally colonized by EMF in commercial nurseries. Powell and Bates (1981) found that the degree of EMF colonization of blueberry roots was related to media sterilization; however, they concluded that the peat based potting mixes they used were low in EMF capable of colonizing highbush blueberry.

The level of root colonization of inoculated plants by EMF showed only slight variation between isolates across different cultivars (Fig. 1B). Four of the seven cultivars had the highest levels of colonization when inoculated with the $O$. griseum isolate, compared to plants inoculated with the other two EMF isolates, while the remainder of the cultivars showed similar levels of colonization when inoculated with any of the isolates. Since the $O$. griseum isolate originated from Vaccinium corymbosum roots, it is possible that root colonization of blueberry by EMF may have some level of host-fungus specificity. Interestingly, plants of 'Bluecrop' and 'Blueray', the closest related cultivars tested, showed similar specificity in colonization responses to inoculation with the different isolates. 'Georgia Gem', which also showed similar specificity in colonization responses to inoculation, has 'Bluecrop' germplasm incorporated into its ancestry back two generations. This differential colonization between cultivars inoculated with the $O$. griseum and other isolates suggest that the type of host-fungus specificity that exists between blueberry and EMF may be linked to differences in ancestry between the cultivars as well as the source of the fungal isolate. In a survey of commercial blueberry nursery plants, Scagel et al. (2005b) found that within a stock type and sampling date, the greatest differences in colonization were found between the northern highbush and rabbiteye cultivars. These types of cultivar-specific differences in colonization could be a result of host-fungus specificity with the natural inocula present in the specific nursery being better adapted for northern highbush cultivars and not naturally causing high colonization of rabbiteye cultivars. In Oregon production fields, 'Powderblue' has also been reported to have low colonization by EMF (Scagel and Yang, 2005).

By inoculating blueberry plants early in container production, we were able to increase root colonization by EMF to around $30 \%$ (Fig. 1). In field production of blueberry in the Oregon, root colonization by EMF can be as high as about50\% (Scagel and Yang, 2005). Others (Golldack et al., 2001; Yang et al., 1998) have also reported similar levels of EMF colonization in blueberry roots in production fields. Lower levels of colonization of blueberry by EMF in our study may also be related to seasonal changes in plant growth and plant age. Scagel (2002) found that EMF colonization of cranberry roots significantly increased from spring until fall, while in contrast, EMF colonization on ericaceous plant species naturally established adjacent to bogs showed colonization levels $>90 \%$ at all sampling dates throughout the growing season. Levels of EMF colonization of cranberry at different times of year also varied with the age of the bog, with older bogs showing larger seasonal differences than younger bogs (Scagel, 2002). Seasonal variation in EMF colonization has also been described for Calluna (Johansson, 2000). With blueberry, increased EMF colonization in the fall could be a result of seasonal variation in root growth of different cultivars. Root production in cranberry occurs after the first flush of new vegetative growth and late in the fall after vegetative growth has ceased for the season (De Moranville, 1992). It is possible that the low levels of colonization by EMF we measured in container grown blueberry plants are related to plant growth during the time of sampling.

Low colonization during nursery production of blueberry may also be due to cultural conditions that inhibit colonization of the fungi that are present whether plants have been inoculated or not (Haynes and Swift, 1985; Johansson, 2000). Others have found that EMF colonization of blueberry varies significantly with the cultivar, rate of fertilizer application, and the amount and type of soil organic matter present in the soil (Czesnik and Eynard, 1990; Eynard and Czesnik, 1989; Golldack et al., 2001; Powell, 1982). Golldack et al. (2001) found that increasing amounts of fertilizer decreased EMF colonization of 'Duke' and
'Reka' cultivars in Germany. The effects of high fertility levels on yield and EMF colonization in field production were also found to be cultivar-specific (Golldack et al., 2001). They found that the highest yield of 'Duke' was correlated with the lowest amount of inorganic fertilizer used during production whereas the highest yield of 'Reka' corresponded to the highest amount of fertilizer used. Increasing fertilization rates decreased EMF colonization of 'Duke' and had little influence on colonization of 'Reka'. This type of cultivar-specific response in sensitivity to EMF colonization by nutrient availability may be responsible for some of the differences in the frequency and intensity of colonization we detected in different cultivars. In container production where fertilizer concentrates nutrient availability around the plant root system, high levels of available nutrients may negatively influence EMF colonization. In our study, plants grown with organic fertilizer may have been nutrient limited and under these conditions colonization was higher, but only with plants inoculated with two of the three EMF isolates (Fig. 1B). Fertilizer type did not influence colonization of noninoculated plants and plants inoculated with the $H$. ericae isolate. This suggests that although nutrient availability may influence colonization, aspects of fungus-host specificity and inoculum availability also play a role in EMF colonization of roots in container production.

Most members of the Ericaceae, including Vaccinium spp., are calcifuge plants that grow naturally in acid soils of low to moderate fertility with nutrients available to plants primarily in organic forms. When we grew blueberry plants with inorganic or organic fertilizer, we found that four ('Bluecrop', 'Blueray', 'Darrow', and 'Earliblue') of the seven cultivars tested grew less when grown with organic fertilizer (Fig. 2A). When grown with organic fertilizers, these four cultivars also took up less total N, P, K, and S (Fig. 3) and their growth may have been limited by uptake of $\mathrm{N}, \mathrm{K}, \mathrm{S}$ and $\mathrm{Cu}$ when noninoculated with EMF (Table 2). Admittedly, the fertilizers used in our study did not provide an equal amount of nutrients to plants and the form of $\mathrm{N}$ was different between the two fertilizers, however fertilizer application rates were similar in regards to fertilizer analysis for total N. When growing with organic fertilizer, plants of all cultivars took up less $\mathrm{N}, \mathrm{K}$, and $\mathrm{S}$ after two growing seasons (Fig. 3A), however lower uptake of these nutrients did not influence total growth of 'Georgia Gem', 'Patriot', or 'Spartan', and total biomass accumulation of noninoculated plants of these cultivars appeared to not be limited by any nutrients we measured (Table 2 ). These three cultivars appeared to be more efficient at using organic sources of nutrients for growth regardless of the level of EMF colonization. The increased efficiency of nutrient use exhibited by these plants is partially related to increased root growth when growing with organic fertilizer (Fig. 2A). Although total biomass of these cultivars was not influenced by fertilizer type, above ground biomass was lower when plants were grown with organic 
fertilizer. This differential partitioning of biomass when grown with organic fertilizer may have implications to grading of nursery stock based on aboveground phenotype, even though root systems of these plants may be larger. In other nursery crops, root system size in relation to above ground size can have a substantial influence on survival and initial growth of plants after transplanting (Cabrera and Devereaux, 1999; Frampton et al., 2002). It is possible that growing these cultivars with organic sources of nutrients may be beneficial to nursery stock quality.

Plants colonized by EMF can absorb $\mathrm{N}$ from compounds unavailable to nonmycorrhizal plants (Stribley and Read, 1974a; Stribley and Read, 1974b) and are thought to improve the general physiological condition of the host plant through enhanced uptake of other nutrients, such as P (Stribley et al., 1975; Stribley and Read, 1976). We found that inoculation of container grown blueberry plants increased total biomass of six of the seven cultivars examined (Fig. 2B) and biomass increases in response to inoculation generally resulted increased root and stem biomass. Inoculation of blueberry plants in a commercial nursery with EMF has been reported to cause measurable changes in root and aboveground plant morphology and biomass partitioning during the first two growing seasons (Scagel et al., 2005b). Yang et al. (2002) also reported that inoculation of 'Elliott' highbush blueberry with EMF enhanced plant growth (higher dry weight and larger canopy volumes), while others, (Reich et al., 1982; Smagula and Litten, 1989; Yang et al., 1998) reported that inoculation with native, unidentified EMF isolates caused no change in growth of blueberry plants. Differences in plant responses to inoculation between these studies and ours could be related to differences in plant culture (e.g., field soil versus soilless potting medium), blueberry cultivar and the fungal isolates used for inoculation. Interestingly, even though we compared three EMF isolates that caused significant interactions between cultivar and isolate in root colonization, total biomass response to the three isolates was similar across cultivars. This suggests that between isolate differences in levels of colonization measured between cultivars that are statistically significant 1) may not be biologically significant, or 2) may cause similar growth responses via different mechanisms. For example, root colonization of cultivar 'Spartan' (which has low bush blueberry in it's ancestry) was increased by inoculation with EMF (Fig. 1A), and this cultivar showed no biomass response to inoculation (Fig. 2B), suggesting that root colonization did not influence growth of this cultivar. However, total uptake of N, P, Zn (Fig. 4), and Fe was lower in plants inoculated with EMF, suggesting that EMF inoculation increased the efficiency of nutrient use, especially when grown with inorganic fertilizer(Table 2) (e.g., more growth with less nutrients). In contrast, the slight increases in growth of 'Patriot' in response to inoculation with EMF appeared to be mainly related to an increase uptake of $\mathrm{P}, \mathrm{Ca}, \mathrm{Fe}$, and $\mathrm{Zn}$. Biomass responses of other cultivars showed a combination of increased uptake and increased efficiency of nutrient use of different nutrients in response to inoculation. Our results suggest that increasing EMF colonization of container grown blueberry plants may not only increase biomass accumulation of plants but also increase the uptake or efficiency of nutrient use in plants and therefore have implications to fertilizer inputs used during nursery production. However responsiveness to EMF inoculation is variable with cultivar and more information is needed to better understand how patterns in nutrient uptake and use of different cultivars in response to EMF can be predicted.

Ericoid mycorrhizal fungi can assimilate both ammonium and nitrate ions and transfer them to their plant symbiont (Bajwa and Read, 1985). In addition to an ability to readily use ammonium and nitrate, EMF can also use amino acids, peptides, proteins, and polymers such as chitin and lignin to transfer substantial quantities of $\mathrm{N}$ to the plant host (Bajwa and Read, 1985; Kerley and Read, 1995, 1997, 1998; Stribley and Read, 1980). We found that when plants were grown with inorganic fertilizer, inoculation with any of the three EMF isolates caused similar increases in root colonization (Fig. 1) and total biomass (Fig. $2 \mathrm{C}$ ), while when plants were grown with organic fertilizer, the $O$. griseum isolate caused larger increases in root colonization and total biomass than plants inoculated with the other isolates. This variation in colonization and growth response to the different isolates when grown with different fertilizer types suggests there may a differential ability or efficiency between fungi to increase uptake or use of different nutrients. Our results showed that in general there was little difference between the EMF isolates we tested on total uptake of macronutrients (Fig. 5) while differences in uptake and accumulation of micronutrients, especially $\mathrm{Fe}, \mathrm{Cu}$, and $\mathrm{Zn}$ were common. Others have reported variation between EMF isolates in their ability to increase microelement (Martino et al., 2003) and macroelement solubility or uptake (Cairney et al., 2000; Midgley et al. 2004). In our study, intra-isolate variation in macronutrient uptake was minimal when given the diverse forms of organic nutrients found in the fertilizer. When noninoculated plants were grown with organic fertilizer, we found that growth of certain cultivars may have been limited by lower uptake or availability of $\mathrm{N}$, $\mathrm{K}, \mathrm{S}$, and $\mathrm{Cu}$ and inoculation with EMF in all cases alleviated this nutrient limitation and nutrient use was either similar to plants grown with inorganic fertilizer, or plants exhibited a more efficient use of nutrients (Table 2).

Analysis of foliar nutrients is a common practice in nursery and field production of blueberry used to assess visual symptoms of nutrient deficiency or potential deficiencies that can limit growth. Although we found that growth of many cultivars may have been limited by lower uptake or availability of N, K, S, and $\mathrm{Cu}$ when plants were grown with organic fertilizer, we found that across all treatments leaf concentrations for all nutrients except $\mathrm{Ca}, \mathrm{Fe}$, and $\mathrm{Cu}$ (Table 1) were in the 'normal' ranges published by others (Ballinger 1966; Clark et al., 1989; Doughty et al., 1981; Strik and Hart, 1997). Published values considered normal for different blueberry growing regions are generally based on field grown plants and concentrations of nutrients in leaves of blueberry can vary with time of season, soil type, canopy position, leaf age, and cultivar (Clark et al., 1989; Clark and Maples, 1990; Eaton and Meehan, 1971; Finn et al., 1993). Even though samples were taken for analysis a little later in the growing season than when commonly recommended, it was somewhat surprising that foliar concentrations of highly conserved macroelements (e.g., N, P, K, and S) were still within the "normal' range even though nutrient availability appeared to be limiting growth of noninoculated plants grown with organic fertilizer. For example, noninoculated 'Bluecrop' grown with inorganic fertilizer had leaf $\mathrm{N}$ concentration of $26.7 \mathrm{mg} \cdot \mathrm{g}^{-1}$ and when grown with organic fertilizer had a leaf $\mathrm{N}$ concentration of $18.6 \mathrm{mg} \cdot \mathrm{g}^{-1}$. Both these values are in a normal range yet biomass of all tissues on 'Bluecrop' were significantly lower when plants were grown with organic fertilizer compared to when they were grown with inorganic fertilizer (Fig. 2A). This suggests that normal values commonly found in field production may not be as valuable in container nursery production where plant age and growth rate as well as cultural factors may interact to create a higher nutrient demand from growth. This means that foliar concentrations of nutrients that might not be limiting in field production and crop yield, may be limiting to growth, potential production efficiency, and crop quality in nursery production.

\section{Literature Cited}

Ballinger, W.E. 1966. Soil management, nutrition and fertiliser practices, p. 132-178. In: P. Eck and N.F. Childers (eds.). Blueberry culture. Rutgers Univ. Press, Brunswick, N.J.

Bajwa, R. and D.J. Read. 1985. The biology of mycorrhiza in the Ericaceae: IX. Peptides as nitrogen sources for the ericoid endophyte and for mycorrhizal and nonmycorrhizal plants. New Phytol. 101:459-467.

Cabrera, R.I. and D.R. Devereaux. 1999. Crape myrtle post-transplant growth as affected by nitrogen nutrition during nursery production. J. Amer. Soc. Hort. Sci. 124:94-98.

Cairney, J.W.G., N.A. Sawyer, J.M. Sharples, and A.A. Meharg. 2000. Intraspecific variation in nitrogen source utilisation by isolates of the ericoid mycorrhizal fungus Hymenoscyphus ericae (Read) Korf and Kernan. Soil Biol. Biochem. 32:1319-1322.

Clark, J.R., D.B.Marx, and D.G. Dombek. 1989. Seasonal variation in elemental content of 'Bluecrop' blueberry leaves. Univ. Ark. Agr. Expt. Stat. Bul. 920.

Clark, J.R. and R. Maples. 1990. Leaf elemental concentration of highbush blueberry cultivars grown on a mineral soil. Fruit Var. J. 44(2):89-92.

Czesnik, E. and I. Eynard. 1990. Mycorrhizal infection level in five cultivars of highbush blueberry (Vaccinium corymbosum L. ). Agr. Ecosys. Environ. 29:67-71.

De Moranville, C.J. 1992. Cranberry nutrients, phenology, and $\mathrm{N}-\mathrm{P}-\mathrm{K}$ fertilization. PhD diss. Univ. Mass., Amherst.

Doughty, C.C., E.B. Adams, and L.W. Martin. 1981. 
High bush blueberry production in Washington and Oregon, p. 25. Wash. State Univ.

Eaton, G.W. and C.N. Meehan. 1971. Effects of leaf position and sampling date on leaf nutrient composition of eleven highbush blueberry cultivars. J. Amer. Soc. Hort. Sci. 96: 378-80.

Eynard, I. and E. Czesnik. 1989. Incidence of mycorrhiza in 4 highbush blueberry cultivars in different soils. Acta Hort. 241:115-119.

Finn, C.E., C.J. Rosen, J.J. Luby, and P.D. Ascher. 1993. Blueberry germplasm screening at several soil $\mathrm{pH}$ regimes. II. Plant nutrient composition. J. Amer. Soc. Hort. Sci. 118:383-387.

Frampton, J., F. Isik, and B. Goldfarb. 2002. Effects of nursery characteristics on field survival and growth of loblolly pine rooted cuttings. S. J. Appl. For. 26:207-213.

Giovannetti, M. and B. Mosse. 1980. An evaluation of techniques for measuring vesicular arbuscular mycorrhizal infection in roots. New Phytol. 84: 489-500.

Golldack, J., P. Schubert, M. Tauschke, H. Schwarzel, G. Hofflich, P. Lentzsch, and B. Munzenberger. 2001. Mycorrhization and plant growth of highbush blueberry (Vaccinium corymbosum L.) on arable land in Germany. Proc. 3rd Intl. Conf. on Mycorrhiza. July 2001. Adelaide, Austral.

Haynes, R.J. and R.S. Swift. 1985. Growth and nutrient uptake by highbush blueberry plants in a peat medium as influenced by $\mathrm{pH}$, applied micronutrients and mycorrhizal inoculation. Scientia Hort. 27:385-294.

Johansson, M. 2000. The influence of ammonium nitrate on the root growth and ericoid mycorrhizal colonization of Calluna vulgaris (L.) Hull from a Danish heathland. Oecologia 123:418-424.

Kerley, S.J. and D.J. Read. 1995. The biology of mycorrhiza in the Ericaceae: XVIII. Chitin degradation by Hymenoscyphus ericae and transfer of chitin-nitrogen to the host plant. New Phytol. 131:369-375.

Kerley, S.J. and D.J. Read. 1997. The biology of mycorrhiza in the Ericaceae: XIX. Fungal mycelium as a nitrogen source for the ericoid mycorrhizal fungus Hymenoscyphus ericae and its host plants. New Phytol. 136:691-700.

Kerley, S.J. and D.J. Read. 1998. The biology of mycorrhiza in the Ericaceae: XX. Plant and mycorrhizal necromass as nitrogenous substrates for the ericoid mycorrhizal fungus Hymenoscyphus ericae and its host. New Phytol. 139:353-359.

Martino, E., S. Perotto, R. Parsons, and G.M. Gadd. 2003. Solubilization of insoluble inorganic zinc compounds by ericoid mycorrhizal fungi derived from heavy metal polluted sites. Soil Biol. Biochem. 35: 133-141.

Michelsen, A., I.K. Schmidt, S. Johanasson, C. Quarmby, and D. Sleep. 1996. Leaf ${ }^{15} \mathrm{~N}$ abundance of subarctic plants provides field evidence that ericoid, ectomycorrhizal and nonectomycorrhizal species access different sources of soil nitrogen. Oecologia 105:53-63.

Midgley, D.J., S.M. Chambers, and J.W.G. Cairney. 2004. Inorganic and organic substrates as sources of nitrogen and phosphorus for multiple genotypes of two ericoid mycorrhizal fungal taxa from Woollsia pungens and Leucopogon parviflorus (Ericaceae). Austral. J. Bot. 52: 63-71.

Molina, R. and J.G. Palmer. 1982. Isolation, maintenance, and pure culture manipulation of ectomycorrhizal fungi, p. 115-129. In: N.C. Schenck (ed.). Methods and priciples of mycorrhizal research. Amer. Phytopathol. Soc.

Moore-Parkhurst, S. and L. Englander. 1981. Mycorrhizal status of Rhododendron spp. in commercial nurseries in Rhode Island. Can. J. Bot. 60:2342-2344.

Powell, C.L. 1982. The effect of the ericoid mycorrhizal fungus Pezizella ericae (Read) on the growth and nutrition of seedlings of blueberry (Vaccinium corymbosum L.). J.Amer. Soc. Hort. Sci. 107:1012-1015.

Powell, C.L. and P.M Bates. 1981. Ericoid mycorrhizas stimulate fruit yield of blueberry. HortScience 16: 655-656.

Read, D.J. 1996. The structure and function of the ericoid mycorrhizal root. Ann. Bot. 77:365-374.

Reich, L.A., R.F. Korcak, andA.H. Thompson. 1982. Effect of two mycorrhizal isolates on highbush blueberry at two soil pH levels. HortScience 17:642-644.

Scagel, C.F. 2002. Mycorrhizal status of sandbased cranberry (Vaccinium macrocarpon) bogs in southern Oregon. Small Fruits Rev. 2(1):31-41.

Scagel, C.F., A. Wagner, and P. Winiarski. 2005a. Frequency and intensity of root colonization by ericoid mycorrhizal fungi in nursery production of blueberry. Small Fruits Rev. (in press).

Scagel, C.F., A. Wagner, and P. Winiarski. 2005b.
Inoculation with ericoid mycorrhizal fungi alters root colonization and growth in nursery production of blueberry plants from tissue culture and cuttings. Small Fruits Rev. (in press).

Scagel, C.F. and W. Yang. 2005. Cultural variation and mycorrhizal status of blueberry plants in nw oregon commercial production fields. Small Fruits Rev. (in press).

Smagula, J.M. and W. Litten. 1989. Effect of ericoid mycorrhizae isolates on growth and development of lowbush blueberry tissue culture plantlets. Acta Hort. 241:110-114.

Stribley, D.P. and D.J. Read. 1974a. The biology of mycorrhiza in the Ericaceae. III. Movement of carbon-14 from host to fungus. New Phytol. 73:731-741.

Stribley, D.P. and D.J. Read. 1974b. The biology of mycorrhiza in the Ericaceae IV. The effect of mycorrhizal infection on uptake of ${ }^{15} \mathrm{~N}$ from labeled soil by Vaccinium macrocarpon Ait. New Phytol. 73:1149-1155.

Stribley, D.P. and D.J. Read. 1976. The biology of mycorrhiza in the Ericaceae. VI. Effects of mycorrhizal infection and concentration of ammonium nitrogen on growth of cranberry (Vaccinium macrocarpon Ait.) in sand culture. New Phytol. 77:63-72.

Stribley, D.P. and D.J. Read. 1980. The biology of mycorrhizae in the Ericaceae. VII. The relationship between mycorrhizal infection and the capacity to utilize simple and complex organic nitrogen sources. New Phytol. 86:365-371.

Stribley, D.P., D.J. Read, and R. Hunt. 1975. The biology of mycorhiza in the Ericaceae. V. The effects of mycorrhizal infection, soil type and partial soil-sterilization (by gamma-irradiation) on growth of cranberry (Vaccinium macrocarpon Ait.). New Phytol. 75:119-130.

Strik, B. and J. Hart. 1991. Blueberry fertilizer guide. Ore. State Univ. Ext. Publ. FG-78.

Yang, W.Q., B.L. Goulart, and K. Demchak. 1998. Mycorrhizal infection and plant growth of highbush blueberry in fumigated soil following soil amendment and inoculation with mycorrhizal fungi. HortScience 33:1136-1137.

Yang, W.Q., B.L. Goulart, K. Demchak, and Y.D. Li 2002. Interactive effects of mycorrhizal inoculation and organic soil amendments on nitrogen acquisition and growth of highbush blueberry. J. Amer. Soc. Hort. Sci. 127:742-748. 